\title{
Commentary: Combined surgery of mitral valve and atrial fibrillation. A demonstrated better alternative
}

\author{
Cipriano Abad, MD, PhD, Stefano Urso, MD, PhD, and Bernardino Clavo, MD, PhD
}

\footnotetext{
From the Department of Medical and Surgical Sciences, School of Medicine, University of Las Palmas de Gran Canaria, Las Palmas de Gran Canaria, Spain.

Disclosures: Authors have nothing to disclose with regard to commercial support.

Received for publication Sept 20, 2018; accepted for publication Sept 20, 2018; available ahead of print Nov 9 , 2018.

Address for reprints: Cipriano Abad, MD, PhD, FEBS (Gen Surg, Hon), EBCTS, Department of Medical and Surgical Sciences, School of Medicine, University of Las Palmas de Gran Canaria, Paseo Blas Cabrara sn, Las Palmas de Gran Canaria 35016, Spain (E-mail: cprnabad2@gmail.com).

J Thorac Cardiovasc Surg 2019;157:1531-2

$0022-5223 / \$ 36.00$

Copyright (c) 2018 by The American Association for Thoracic Surgery

https://doi.org/10.1016/j.jtcvs.2018.09.094
}

In this issue of the Journal, Kim and coworkers ${ }^{1}$ present a retrospective clinical study of 1229 consecutive patients with rheumatic mitral valve disease and atrial fibrillation (AF) who underwent mitral valve surgery. Among them, 812 patients $(66.1 \%)$ received concomitant surgical ablation (SA) of AF and 417 (33.9\%) underwent mitral valve surgery alone. Comparing the ablation group with the no ablation group, the first showed better results in terms of lower early mortality $(1.2 \%$ vs $2.4 \%)$, overall mortality ( $2 \%$ vs $4.1 \%$ ), rate of composite valve complications (reoperation, hemorrhagic events, infective endocarditis; $2.2 \%$ vs $3 \%$ ), and rate of postoperative $\mathrm{AF}$ occurrence $(6.1 \%$ vs $29 \%)$. Freedom from the first AF occurrence at 5 years were $76 \%$ in the ablation group and $4.5 \%$ in the no ablation group $(P<.001)$. Freedom from thromboembolic events at 10 years were $92.4 \%$ in the ablation group and $89.3 \%$ in the no ablation group, respectively. Overall survival at 10 years were $83.2 \%$ in the ablation group and $75.2 \%$ in the no ablation group $(P<.001)$. The limitations of the publication are as follows: (1) it is a retrospective and observational study, (2) rheumatic mitral valve disease is decreasing and uncommon to observe today in western countries, and (3) the heterogeneity of the article with different surgical approaches (sternotomy, 1053; right thoracotomy, 176), atrial incision, conduct of cardiopulmonary bypass, and myocardial protection strategy; operation executed by different surgeons; different valve surgery performed (mitral valve repair, mechanical valve replacement, bioprosthetic valve replacement); and different methods of AF surgical correction. Nonetheless, Kim and coworkers ${ }^{1}$ must be acknowledged for a thorough study of an impressively large series of patients with rheumatic mitral valve disease in association with AF submitted to cardiac surgery. This article probably represents the largest number of patients and the longest follow-up in this field.

Performance of SA of AF in patients undergoing mitral valve surgery has been associated with a better outcome.

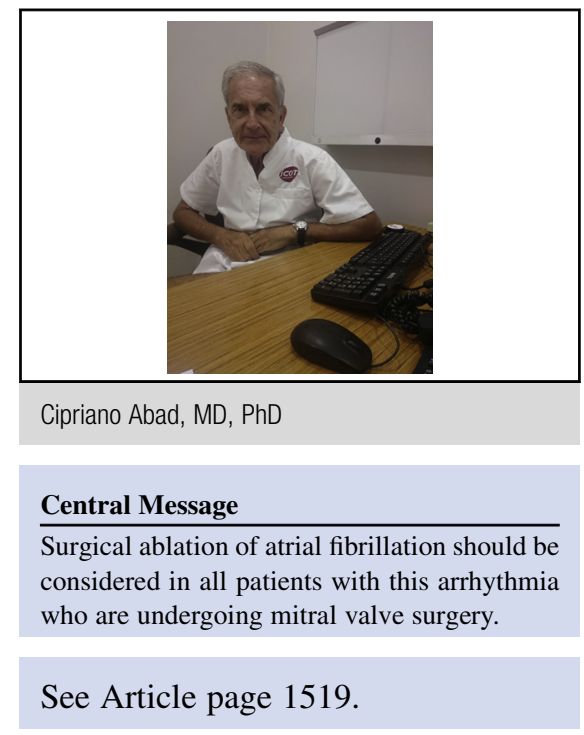

In a selected review of the Society of Thoracic Surgeons database from July 2011 to June 2014, a total of 42,066 surgical patients were found to have undergone SA of AF. Patients undergoing mitral valve surgery had the highest rates of SA. After propensity matching, SA was associated with a reduction in relative mortality and risks of 30-day mortality and stroke. ${ }^{2}$ McClure and associates, ${ }^{3}$ in a systematic review and meta-analysis, found that SA of AF in general cardiac surgical patients was in close relation with greater freedom from AF at 12 months; however, no significant differences were seen in mortality and stroke. Suwalski and colleagues ${ }^{4}$ recently communicated a retrospective study of 11.381 patients with AF undergoing mitral valve surgery. Of the included patients, $2449(21.5 \%)$ underwent SA; after propensity matching, SA was associated with increased survival. According to Sternic and colleagues, ${ }^{5} \mathrm{SA}$ of AF must accompany most mitral valve operations.

In their report, Kim and coworkers ${ }^{1}$ achieve a significant benefit in the group of patients managed by concomitant mitral valve surgery and open $\mathrm{AF}$ ablation. This observation confirms, reinforces, and demonstrates that combined surgery is the best alternative. Kim and coworkers ${ }^{1}$ clearly provide interesting and useful information to surgeons and physicians involved in mitral valve surgery.

\section{References}

1. Kim WK, Kim HJ, Kim JB, Jung SH, Choo SJ, Chung CH, et al. Concomitant ablation of atrial fibrillation in rheumatic mitral valve surgery. J Thorac Cardiovasc Surg. 2019;157:1519-28.e5. 
2. Badhwar V, Rankin JS, Ad N, Grau-Sepulveda M, Damiano RJ, Gillinov AM, et al. Surgical ablation of atrial fibrillation in the United States: trends and propensity matched outcomes. Ann Thorac Surg. 2017;104:493-500.

3. McClure GR, Belley-Cote EP, Jaffer IH, Dvirnik N, An KR, Fortin G, et al. Surgical ablation of atrial fibrillation: a systematic review and meta-analysis of randomized controlled trials. Europace. 2018;20:1442-50.
4. Suwalski P, Kowalewski M, Jasinski M, Staromłyński J, Zembala M, Widenka K, et al. Survival after surgical ablation for atrial fibrillation in mitral valve surgery: Analysis from Polish National Registry of Cardiac Surgery Procedures (KROK). J Thorac Cardiovasc Surg. September 7, 2018 [Epub ahead of print].

5. Sternik L. Never forget to consider atrial fibrillation during mitral valve surgery. $J$ Thorac Cardiovasc Surg. August 6, 2018 [Epub ahead of print]. 